\title{
EN EL CENTRO DEL CANON : LEOPOLDO LUGONES EN LAS ANTOLOGÍAS POÉTICAS ARGENTINAS (1900-1938)
}

\section{An íBAL SALAZAR An GLADA*}

\section{RESUMEN}

La historiografía literaria argentina, cuyo proceso de maduración se inicia en torno a 19151920, nos muestra a Leopoldo Lugones como a uno de los grandes artífices dela modernidad poética en el contexto cultural de Hispanoamérica, y también como al escritor totalizante que orada todos los caminos estéticos, más allá de modas y modismos. En este sentido, la imagen preponderante que las antologías poéticas argentinas proyectan de Lugones en un período clave de las letras nacionales (1900-1938) va a ser determinante respecto al proceso de canonización del autor. El caso particular de Lugones, puesto a examen desdelas antologías, presenta una peculiaridad poco común: la de resistir indemne a los embates del tiempo y de la crítica hasta lograr convertirse en una de las pocas certezas unánimemente aceptadas dentro del canon literario argentino.

Palabras claves: Leopoldo Lugones, antologías, historia literaria, canon, Argentina, poesía.

\section{ABSTRACT}

Argentinian literary historiography, which began to mature around 1915-1920, shows us Leopoldo Lugones as one of the great representatives of the poetic modernity in Latin America's cultural context; he also stands for the writer who experiments with all the aesthetic styles, regardless of fashions and idioms. In this sense, the main image that we receive of Lugones in Argentinian poetic anthologies, in a key period of national literature (19001938 ) is essential concerning the process of the author's canonization. The particular case of Lugones, thoroughly revised sincethe anthologies, shows a rare peculiarity: he has persisted unharmed throughout time and survived literary criticism until he has become one of the few certainties unanimously accepted within the Argentinian literary canon.

Keywords: Leopoldo Lugones, anthologies, literary history, canon, Argentina, poetry.

Recibido: 18.04.2005. Aprobado: 31.05.2005.

*Dr. en Literatura H ispanoamericana. Profesor en la Facultad de Filología Hispánica de la Universidad de Sevilla. Sevilla, España. E-mail: anibalsalazar39@hotmail.com 


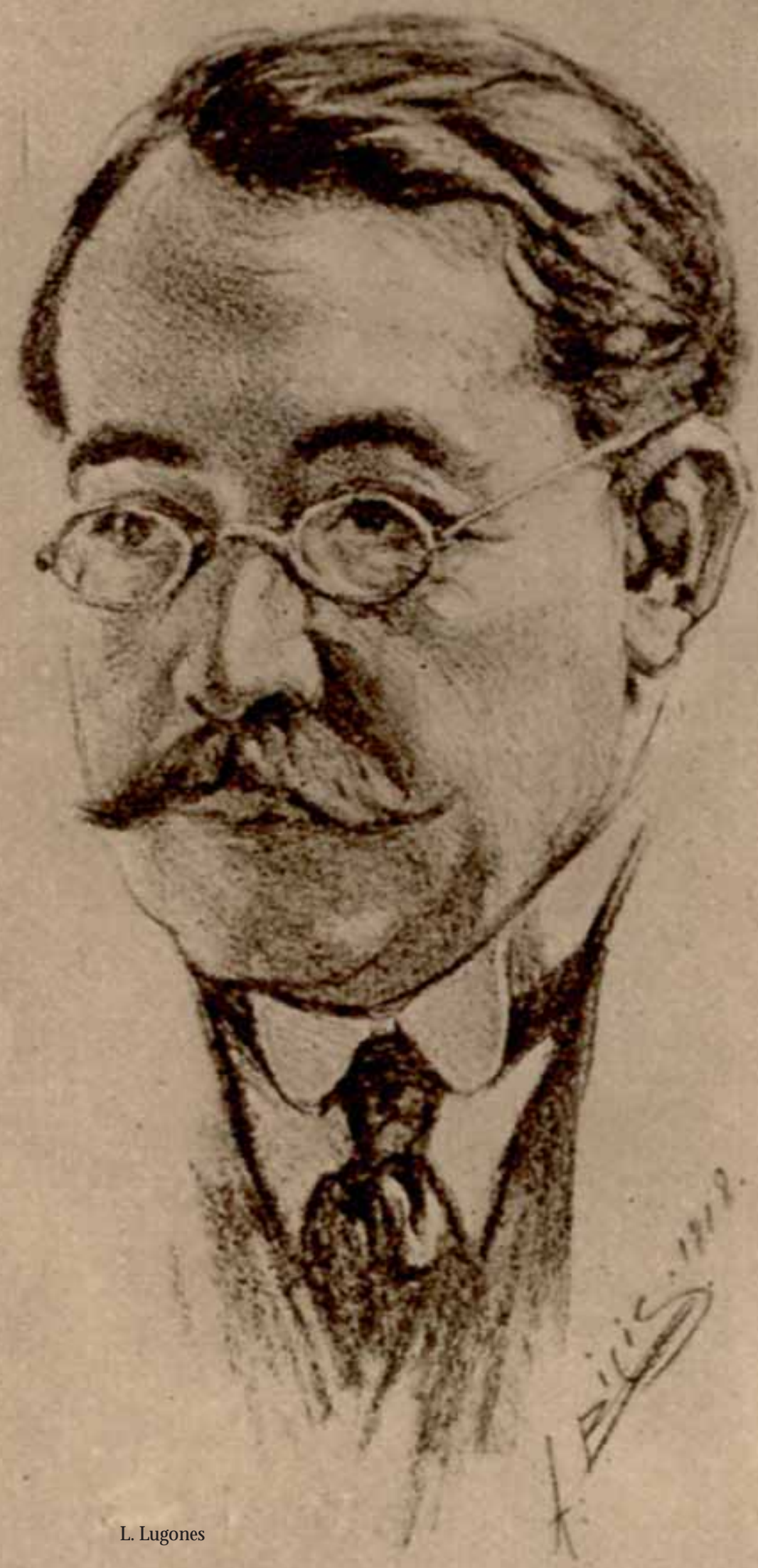


Fue la impresionante aparición de un

bólido en nuestra modesta literatura.

JuAn P. Ramos

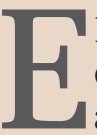

L PRESENTE artículo persigue como objetivo abordar el proceso de canonización de una de las figuras más representativas de la cultura argentina moderna como es Leopoldo Lugones, atendiendo en concreto a su poesía y al modo en que las antologías poéticas reflejan el lugar que ocupa dicho autor en el canon literario nacional. Como las historias literarias, las antologías son partefundamental de un vasto aparato discursivo que opera en la formación detoda nación moderna a través de un canon, el cual expresa unos valores precisos referentes a una identidad común (Cella, 1998: 10). La función de este tipo de obras es la de definir un "nosotros" a través de un complejo sistema de inclusiones y exclusiones, constituyendo cada antología en concreto un ejercicio de selección que marca aquello que debe permanecer dentro y lo que debe quedar fuera. Ahora bien, lejos del carácter sacro, unívoco, inamovible al que remite el étimo del término, debemos pensar el canon literario como multiplicidad y variación. "No hay canon, sino cánones diversos, sistemas que se complementan, sustituyen y suplantan. M ejor, sistemas y valores que se han constituido, se han suplantado", señala Pozuel o Yvancos (1996: 4). Con cada nuevo trabajo se privilegia una determinada línea estética al tiempo que se solapan otras, un hecho en ocasiones más político eideológico que estético y que sin duda marca ala postre la formación del canon literario, o mejor dicho: la formación de uno de los cánones posibles.

El caso particular de Lugones, puesto a examen desdelas antologías, presenta una peculiaridad: la de resistir indemne a los embates del tiempo, a las rencillas culturales, a las inquinas con nombre y apellido, hasta lograr convertirse en una de las pocas certezas unánimemente aceptadas, verdadera piedra de toque de la moderna literatura argentina. A la hora de estudiar la imagen canónica del escritor, y dada la necesidad de acotar un corpus antológico preciso, he tenido en cuenta un arco temporal que comprende desde finales del siglo XIX (atendiendo a las antologías de alcance continental que se publican en este momento) hasta la década del 30 de la siguiente centuria, si bien en el apartado final se incluyen referencias puntuales a la suerte que corre la imagen del escritor post mortem -Lugones fallece en 1938-. Una imagen que en ningún caso deja de ser controvertida, en vida o en muerte, en parte debido a la imposibilidad de disociar al escritor del oficiante político, hecho que sin duda llega a desvirtuar la calidad de la obra lugoniana (al menos para un núcleo determinado de sus contemporáneos, y aun para la crítica posterior), cuestionándose en algún caso su proyección en las nuevas generaciones surgidas a partir de 1910. Pero igual mente, en un sentido inverso, conviene recordar que es precisamente el liderazgo ideoló- 
gico del escritor el que en buena parte le ha granjeado un lugar distinguido en la cultura argentina, al confundirse sus méritos literarios con su prestigio intelectual.

\section{ENTRE CORDOBA Y BUENOSAIRES: LA UNCION DEL POETA HACIA FINALESDEL SIGLO XIX}

Antes de profundizar en las antologías poéticas propiamente argentinas, publicadas dentro o fuera del país, se hace necesario un acercamiento puntual al panorama de las antologías continentales de finales del siglo XIX, espacio donde deberastrearse la prehistoria del proceso decanonización de Lugones, en concreto a partir de Joyas poéticas americanas. Es esta casi con seguridad la primera obra de carácter antológico que recoge textos de un por entonces joven Lugones recién Ilegado a la capital desde su provincia natal, Córdoba. Su autor es el poeta, crítico y periodista cordobés Carlos Romagosa (1897), figura que participa muy directamentedel fervor modernista en aquellos años finales del siglo XIX en que Darío visita Argentina ${ }^{1}$, cuando la nueva estética está aún en ciernes, prefigurada ya en algunas personalidades literarias destacadas del continente(J oséM artí, M anuel Gutiérrez Nájera, Julián del Casal, José Asunción Silva, etc.). El año 1896 es, como tantas veces se ha dicho, una fecha clave y decisiva en el desarrollo de los nuevos modos artísticos, no sólo por lo que concierne a Argentina sino a la cultura hispánica en general. Es el año de publicación de Los raros y Prosas profanas, dos libros esenciales que ven la luz en BuenosAires y que afianzan el nuevo credo en la voz de Darío. Es también 1896 el año preciso en que Lugones se instala en la capital y se da a conocer en los círculos ateneístas. Por aquel entonces el escritor cordobés gozaba de cierta reputación como periodista local bajo el seudónimo de "Gil Paz", cuyos comentarios afilados eran de sobra conocidos. Afecto a la revolución socialista, en su provincia natal había protagonizado alguno que otro altercado de orden social, haciendo gala ya entonces de un talante político enervado que lo llevó a enfrentarse con las autoridades locales. Una vez se instala en Buenos Aires, Ilama enseguida la atención deD arío - esteve en él un Spectacle magnifique, quien en mayo de 1896 publica en El Tiempo una breve semblanza del joven escritor, con un título inequívoco: "Un poeta socialista: Leopoldo Lugones". Este texto constituye una primera impronta de Lugones, a quien Darío no duda en presentar como un "sublevado", un "fanático", un "revolucionario" cuya arrolladora personalidad y encendidos versos prefiguran una

\footnotetext{
${ }_{1}^{1}$ Para un acercamiento a la figura de Carlos Romagosa, prácticamente olvidada en los manuales de historia literaria y monografías dedicados al modernismo, consúltese el artículo de García Morales (1998).
} 
de las mayores promesas del continente (otros, sin embargo, tras oír sus versos en el Ateneo lo declararon "decadente de remate"). En 1912, Darío rememora en su Autobiografía la llegada de aquel joven anárquico a la capital:

Un día apareció Lugones, audaz, joven, fuertey fiero, como un cachorro de hecatónquero que viniera de una montaña sagrada. Llegaba de su Córdoba natal, con la seguridad de su triunfo y de su gloria. Nos leyó cosas que nos sedujeron y nos conquistaron. [... ] Yo agité palmas y verdes ramos en ese advenimiento; y creí en el que venía, hoy crecido y en la plena y luminosa marcha de su triunfante genio (Darío, 1950b: 130).

La imago evangélica que proyecta Darío - la entrada de Jesús en Jerusalén- no deja lugar a dudas sobre la promoción de Lugones: él es el anunciado M esías que espera la América nueva. El Walt Whitman hispanoamericano, dirá en otra ocasión. El descubrimiento de Lugones anteel público americano es, a los ojos de Darío, providencial en la encrucijada del fin de siglo. Una visión mesiánica que es anunciada ya en la serie de retratos realizados por Darío bajo el título de Cabezas, donde encontramos un panegírico de Lugones redactado en 1911 (Darío, 1950a). En esta nueva semblanza, que en cierto modo vendría a paliar la ausencia del escritor cordobés entre los raros darianos (Lugones no escondió su enfado ante Darío sobre este asunto), el vatenicaragüense concedeal poeta de Córdoba un lugar de privilegio en la historia de las letras y el pensamiento americanos:

Listo para todos los combates, apolíneo, hercúleo, perseico, davídico, ello trasmutado en sangre neomundial, su iniciación en la orden del Artequeda como un acontecimiento en la historia del pensamiento hispanoamericano, y no es uno de mis menores orgullos del haberme tocado ser, en días floridos, Anquises del tal Marcelo.

$[\ldots]$

No creo yo que en nuestras tierras de América haya hoy personalidad superior a la de Leopoldo Lugones, quien, antes de llegar al medio del camino de la vida, se ha levantado ya inconmovible pedestal para el futuro monumento (Darío, 1950a: 992).

Si en su Autobiografía Darío recreaba un conocido pasaje evangélico, en este otro texto se valdrá de la tradición clásica al mostrarse orgulloso en su papel de Anquises. Ello remite directamente a un pasaje de la Eneida (VI, 883) en donde el espíritu de Anquises, padre de Enéas, se hace presente en los Campos Elíseos para hablarle a su hijo sobre los misterios del origen del mundo y de la vida ad Inferos, y también para señalar y alabar a aquellosque habrán de convertirse en los grandes héroes de la Roma imperial, entre los que destaca el joven M arcelo, nieto del emperador Augusto. El desciframiento 


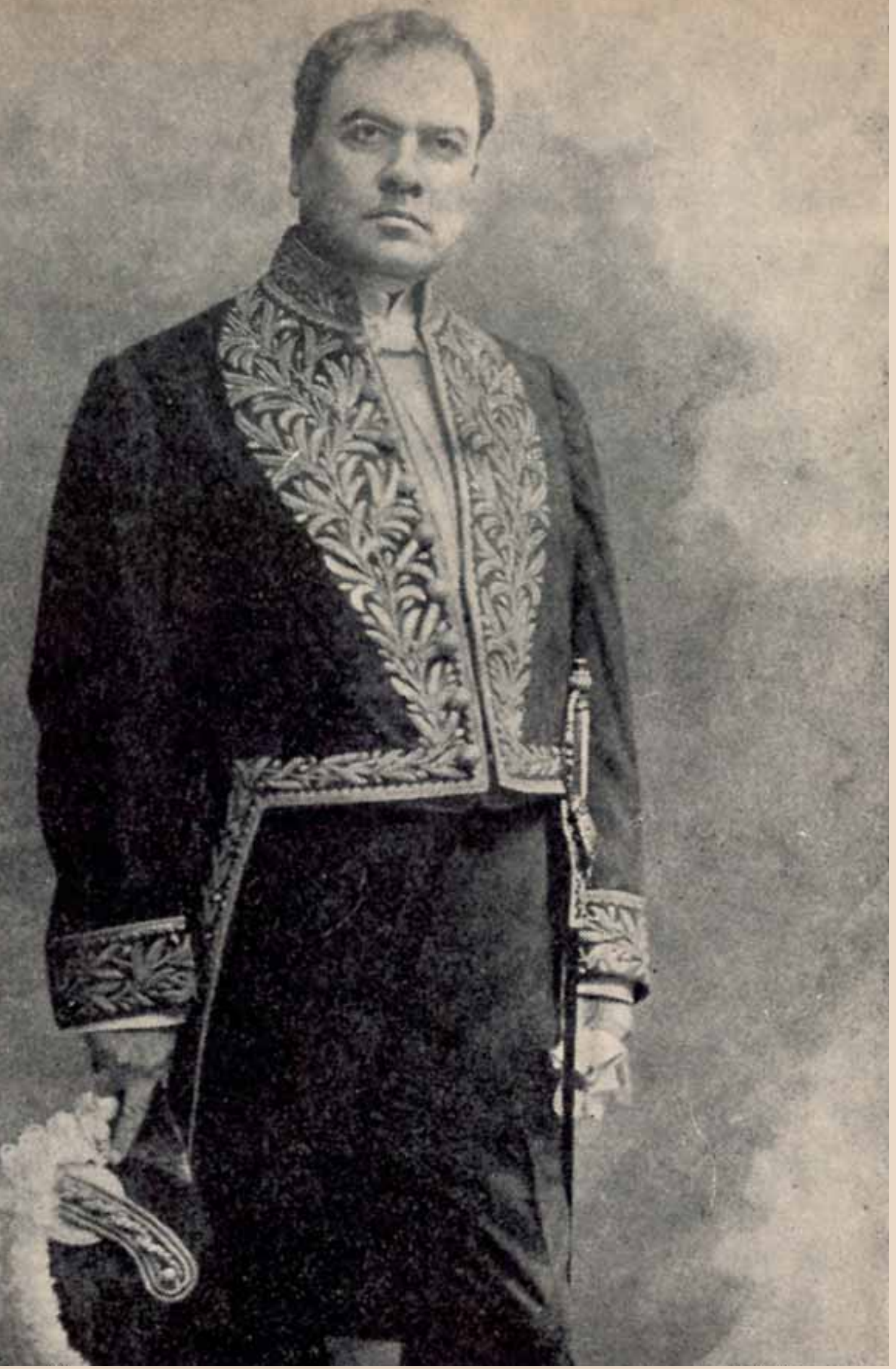


de los símbolos ( $M$ arcelo/Lugones; Roma/América) no deja lugar a dudas sobre la misión que Darío proyecta en la persona de Lugones, como una encarnación de él mismo. La participación decisiva de Darío en el diseño y construcción de ese "pedestal para el futuro monumento" a Lugones queda manifiesta, como puede verse, en esta serie de escritos laudatorios publicados entre finales del siglo XIX y el tercer lustro del XX. El proceso de canonización del escritor cordobés encuentra en dichos textos los pilares de un edificio que desde la propia base - Las montañas del oro (1897)- empieza a ser admirado por su fortaleza y vitalidad. Darío es el aval necesario que necesita el escritor para ingresar en la "Catedral de las glorias argentinas". El camino de consagración está ya trazado.

En este itinerario inicial no debe olvidarse la intervención decisiva de Carlos Romagosa, quien sabiendo de las inquietudes de su pai sano cordobés, de su natural deseo de marchar a la capital para hacer carrera, dará al escritor una carta de recomendación dirigida a Mariano de Vedia, amigo personal de Romagosa y hombre muy relacionado con los círculos políticos e intelectuales bonaerenses ${ }^{2}$. En un tono profético similar al que poco después usará D arío, se expresa Romagosa en la mencionada carta al hablar de Lugones. No sólo aparece allí el escritor señalado como la gran promesa nacional y americana, sino como una realidad hecha presente, ubicado ya entrelo más granado dela joven poesía continental: "D entro depocos años, cuando se citen los más inspirados y originales poetas americanos, se citará también a Lugones, en primera línea". Y algo más adelante: "H oy por hoy, no vacilo en afirmarle que en nuestra patria no tenemos un poeta, de la edad de Lugones, que tenga ni más vuelo en la inspiración, ni más originalidad y vigor en la forma". Algunos meses después de redactar esta carta, Romagosa actuará de oficiante en uno de los actos colectivos más significativos de entre los celebrados en el fin de siglo, en aquellos días en que se fraguaba el modernismo; un acto germinal muy en estrecha relación con la ya citada antología Joyas poéticas americanas. En el Ateneo de Córdoba, y antela presencia misma del vatenicaragüense, Romagosa es el encargado de abrir la velada literario-musical que se celebra en honor del ilustre poeta

\footnotetext{
${ }^{2}$ Dicha carta aparece recogida íntegramente en la biografía de Lugones que escribe su propio hijo (Lugones, 1949: 86-89). Las citas que aparecen en adelante referidas a la carta en cuestión están tomadas de esta obra.

${ }^{3}$ El discurso de Romagosa, quelleva por título significativo "El simbolismo", aparece reproducido íntegramente en García M orales (1998: 105-114). El verdadero motivo de aquella velada cordobesa tiene que ver con los ataques vertidos contra la figura de Darío por parte de cierto periodista conocido por el seudónimo de "Gil Guerra" -reverso del "Gil Paz" tras el queseoculta Lugones, cuyos comentarios condenatorios recoge la prensa local de aquellos días. Por entonces, los jóvenes defensores del nuevo arteeran vistos como unos decadentes, amantes de lo francés y enemigos de toda tradición. Las críticas llegaron a oídos de Darío y su séquito, por lo que un nutrido grupo de prosélitos del poeta nicaragüense decidieron organizar en la misma Córdoba un acto de desagravio.
} 
visitante, Rubén Darío ${ }^{3}$. Corría el mes de octubre de 1896 y aún no sehabía publicado Prosas profanas en formato libro (sí habían aparecido en diversas revistas americanas algunos de los textos que componen la obra). En palabras de García M orales, el homenaje tributado a Rubén Darío en la emblemática provincia "puede considerarse como uno de los pocos actos colectivos del modernismo hispanoamericano, en el que un grupo de jóvenes defendió públicamente sus ideas y proclamó el liderazgo de Darío" (1998: 86). Y junto a la consagración del autor de Azul..., el encomio público de un joven poeta nacido en la provincia cordobesa: Leopoldo Lugones, quien estaba llamado a convertirse en una de las figuras más relevantes dentro del panorama cultural hispanoamericano. Romagosa repasa en su discurso uno por uno aquellos países que, gracias a determinadas actuaciones individuales, asoman a la modernidad poética: M éxico, Cuba, Colombia, Bolivia, Argentina. Al llegar a esteúltimo, donde por tratarse de un panorama quelees mayormente conocido se detiene al go más, menciona lo mejor de la tradición poética nacional: Esteban de Luca, José M ármol, Echeverría, Guido y Spano, Ricardo Gutiérrez, Rafael O bligado, entreotros; y seguidamentedestaca tres figuras principales de la moderna poesía argentina: Olegario $\mathrm{V}$. Andrade, Pedro B. Palacios "Almafuerte" y la gran promesa por aquel entonces, Leopoldo Lugones. "Este último poeta, de naturaleza impetuosa y agresiva, y de labor vigorosa, vibrante y resplandeciente, es un producto genuino y original del moderno movimiento literario - poeta que ha sido presentado ya gentilmente a la admiración y a la esperanza de las letras americanas, por la pluma lapidaria de Rubén Darío" (en García Morales, 1998: 112-113). Puede señalarse este momento como el inicio del proceso de ascensión y glorificación de Lugones, quien hacia los años 20 llega a alcanzar el estatus de autor canónico en el ámbito de las letras argentinas (e hispanoamericanas, habría que añadir necesariamente).

Por lo que concierne a Joyas poéticas, incluye a un total de treinta y dos poetas argentinos, de los cuales muchos de ellos pasaron muy pronto al olvido -Eduardo Gutiérrez, José M iró, Juan M ateo O Imos, entre otros, y desdeluego nunca llegaron a formar partedel canon poético nacional. En cuanto a Darío, incluido con un número destacado de composiciones, si bien aparece recogido bajo la nacionalidad nicaragüense que le corresponde, debe sin duda asociarse su figura a la realidad poética de Argentina, donde acaba deaparecer Prosas profanas, libro a partir del cual se afianza la nueva estética (no en vano la mayor parte de los veintidós poemas que se recogen deDarío pertenecen a esta obra). No es un hecho casual que sean Darío y Lugones los poetas con mayor representatividad en la antología. Ello indica un camino, una dirección. Lugones, "ese genio en flor" que acaba de dar a conocer su primer poemario, recogeel testigo del maestro: "Sus cantos no tienen semejantes en América ni por sus energías, ni por sus ímpetus, ni por sus fulgores, ni por sus sombras", señala Romagosa. Estos señalamientos muestran 
deforma inequívoca la intencionalidad del antólogo: marcar históricamente los inicios de la nueva estética, que entonces tiene su epicentro en Argentina, y reivindicar para ella un lugar de honor en la historia.

Muy distinto tratamiento, exactamente ninguno, recibe Lugones en la Antología americana de M ontaner y Simón, editada en Barcelona en el mismo año que se publica Joyas, 1897. No en vano señala Romagosa esta obra como ejemplo paradigmático de aquellas antologías que por su deficiente composición y su escasa actualidad han desvirtuado el verdadero significado de las letras hispanoamericanas (Romagosa, 1897: X). Lo cierto es que el crítico argentino contaba con una valiosa ventaja frente a los autores de la Antología americana: el contemplar in situ el nacimiento y desarrollo de la nueva estética, denominada ya por entonces modernismo. El distanciamiento de M ontaner y Simón respecto a la realidad poética americana se pone de manifiesto en la escasa atención prestada a Rubén Darío (apenas aparece algún texto de Prosas profanas) y la sonada ausencia, entre otras no menos sancionables, de Lugones, quien en el mismo año de publicación dela antología da a conocer Las montañas del oro. Ello demuestra un total desconocimiento de lo que en aquellos días se está fraguando muy especialmente en Argentina.

\section{EL "PONTIFICADO LITERARIO" DE LUGONES EN TORNO AL CENTENARIO}

Al valorar las antologías poéticas argentinas publicadas dentro y fuera del país, cabe poner de relieve el modo en que a lo largo de las dos primeras décadas del siglo XX la figura de Lugones va cobrando cada vez mayor altura, muy por encima de otros muchos escritores coetáneos sobre los que planea ya por entonces su alargada sombra. Es cierto que es en estas dos décadas donde se concentra la obra lugoniana más reconocida, literaria o no: El imperio jesuítico (1904), Los crepúsculos del jardín (1905), La guerra gaucha (1905), Las fuerzas extrañas (1906), Lunario sentimental (1909), Laslimaduras de H ephaestos (1910), O das seculares (1910), Didáctica (1910), H istoria deSarmiento (1911), Elogio deAmeghino (1915), El payador (1916) o El libro de los paisajes (1917), entre otras obras publicadas por estos años. Apadrinado por el excelso Darío, respetado en los círculos intelectuales más reputados de Buenos Aires, Lugones desempeñará un papel destacado en los actos conmemorativos del Centenario (1810-1910). Por entonces mostraba el escritor sus inquietudes nacionalistas en torno al futuro de Argentina y al papel que ésta debía jugar en la escena internacional ${ }^{4}$. Lejos ya del arrebato

\footnotetext{
${ }^{4}$ Las cel ebraciones suntuosas que a lo largo de 1910 rodearon al Centenario de la Independencia argentina contaron con el respaldo de importantes sectores de la oligarquía burguesa, embar-
} 
visionario de su primer poemario, lejos también de la prefiguración vanguardista del Lunario, la poesía de Lugones toma hacia 1910 un cariz cívico y pedagógico a través de un discurso estético que, puesto al servicio de una clara ideología, busca en la educación patriótica el progreso y la fuerza dela "Grande Argentina".

Antes deabordar la quees considerada como la antología del Centenario por antonomasia: la Antología de poetasargentinos (1910) de Juan dela Cruz Puig, cabría comentar un trabajo anterior de comienzos del siglo XX: El Parnaso argentino de José León Pagano (1904). Esta obra forma parte de una serie interesante de Parnasos publicados por la casa editorial M aucci a lo largo de la primera mitad del siglo, el primero de los cuales es el Parnaso argentino de Guillén de Cardona, de 1903. El Parnaso de Pagano, publicado tan sólo un año después que el anterior, es la primera antología nacional que recoge por completo la pléyade de modernistas argentinos cercanos a Darío. Amante de todas las manifestaciones del arte, incansable viajero de ida y vuelta, Pagano es un testigo presencial de primer orden queen su obra antológica rinde tributo a quienes por entonces compartían con él unas mismas inquietudes estéticas. Si bien a través de esta antología se nos da a conocer en su faceta de crítico y ensayista literario, en realidad Pagano se dedicó profesionalmentea la pintura, ámbito en el cual también ejerció como historiador y crítico. Hacia 1895, tras regresar de un viaje de estudios por Italia, Pagano encuentra en la capital bonaerense un ambiente artístico-literario favorable a las ideas que se desarrollan por entonces en Europa. Dado el aire de época en que desarrolla su obra artística y los círculos intelectuales que frecuenta, no es raro que Pagano rinda en su obra tributo a los poetas fin de siglo que convergen en Buenos Aires. Así, junto a los escritores neoclásicos y románticos que forman parte de la tradición antológica en Argentina, y al lado de al gunos de los nombres más representativos del 80 , el antólogo reúne a los poetas que formaron parte del grupo de Darío en sus años argentinos, todos ellos más o menos afectos al "programa intelectual" que por entonces lleva a cabo el nicaragüense: Roberto J. Payró (aunque era mejor

gada por un crecientesentimiento nacionalista. Tan ilustre conmemoración había deadquirir una dimensión internacional que mostrara al mundo la profunda transformación social y económica que experimentaba Argentina desde los años 80. Este efecto de modernidad, ilusorio en parte, vino dado por la materialización de las políticas progresistas aplicadas en la segunda mitad del siglo XIX, a través de las cuales se impulsaron programas de expansión social, territorial y económica. La concentración de grupos inmigratorios en los núcleos urbanos más prósperos, especialmente en la capital del país, traería consigo un rápido auge de la ciudad. Por su parte, aquella elite tradicionalista y conservadora que dirigía sus esfuerzos en la implantación de una conciencia nacional burguesa vio en la masa inmigratoria urbana, organizada en partidos y sindicatos de izquierda, la desestabilización de las estructuras estatal es y la dispersión de la identidad nacional, ya de por sí incierta. Surge entonces con fuerza, por parte de determinados sectores de la burguesía, el orgulloso discurso nacionalista y patriótico que pone de relievelas virtudes y grandezas del país y señala asimismo la lacra que ha de ser reducida. 


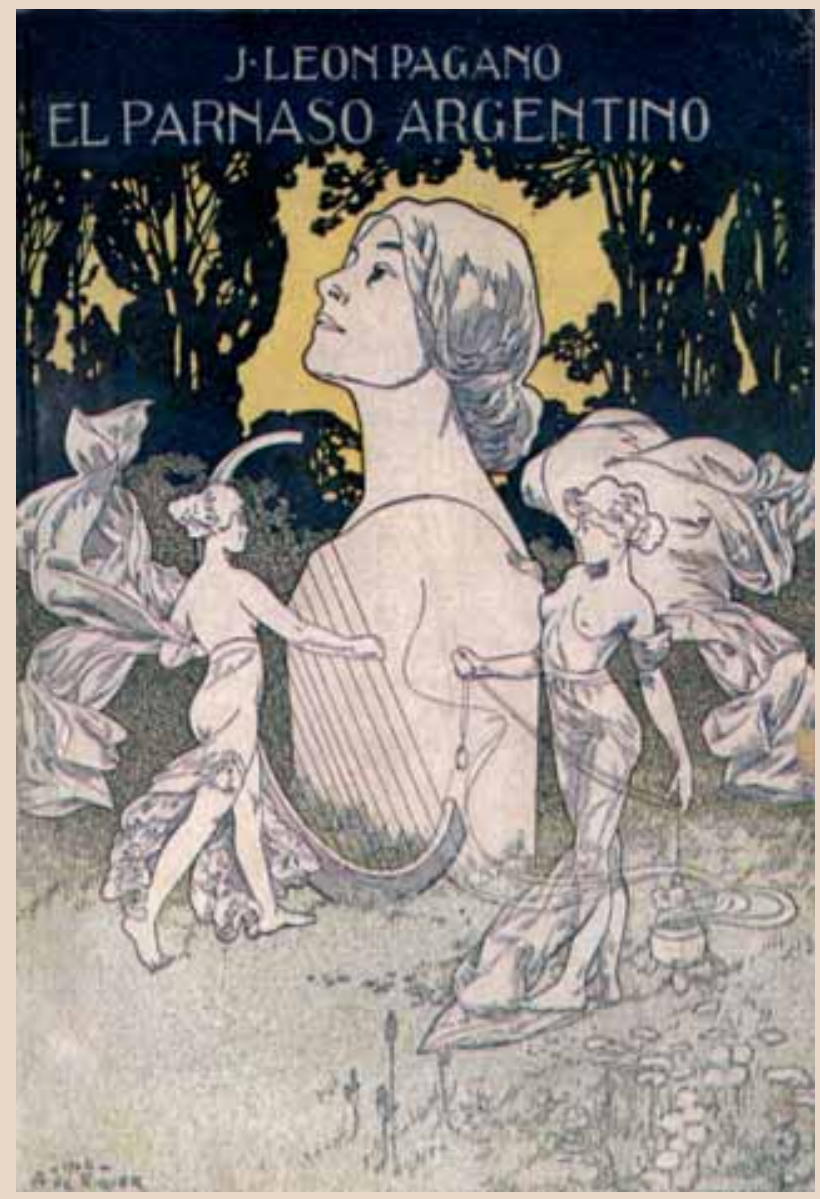

prosistaquelírico);Alberto Ghiraldo, Lugones, Carlos Ortiz, Leopoldo Díaz, Angel de Estrada, Pedro J. Naón, Fernández Espiro y el poeta uruguayo de origen italiano Antonino Lamberti, quien compuso con Darío el soneto "Roma". El Parnaso argentino de Pagano combina, pues, la mejor tradición decimonónica de los Cancioneros y Parnasos patrióticos con una sustanciosa representación de la más moderna poesía que por entonces se está escribiendo en Argentina. Bien es cierto que en esta antología no aparece ningún comentario explícito sobre Lugones (las notas bio-bibliográficasson escuetas y la introducción al libro es un texto rescatado de Juan María Gutiérrez); no obstante, es evidente que el reconocimiento de los poetas modernistas supone dejar constancia del paso de Darío por Argentina, de

${ }^{5}$ Algunos de estos escritores modernistas, como es el caso de Leopoldo Díaz, Carlos Ortiz, Fernández Espiro o Lugones, ya habían sido incluidos entre las Joyas de Romagosa. Se trataba en este caso de un antólogo que, como José León Pagano, conocía muy de cerca el movimiento modernista en Argentina y seguía la estela de D arío. 
su predicamento estético-espiritual entre la juventud del momento y de la importante labor cultural que aquélla realiza, en la que Lugones fue parte fundamental implicada.

Por cuanto se refiere a la Antología de poetas argentinos de Puig, viene a ratificar la preponderancia de Lugones en las letras nacional es que ya apuntara Romagosa a finales del XIX en sus J oyas. Atendiendo a la fecha de publicación de la obra y a los propósitos manifiestos que persigue, puede considerarse la antología de Puig como uno de los exponentes culturales del denominado "espíritu del Centenario", surgida en un contexto sociohistórico y cultural complejo. La obra consta de diez voluminosos tomos, a través de los cual es se levanta una perfecta arquitectura de la historia poética argentina desde los tiempos de la Colonia hasta principios del siglo XX. Sin embargo, a diferencia del Parnaso de Pagano, es muy escasa, casi nula, la representatividad de la poesía modernista. Junto a "Almafuerte", esa rara avis tan difícil de clasificar, aparecen recogidos en el tomo X Leopoldo Díaz y Lugones como representantes del modernismo argentino. M uy poco significativo, se entenderá, teniendo en cuenta lo que había supuesto y seguía representando en su declive el movimiento modernista en Argentina. Del primero de ellos apenas destaca el antólogo nada más allá de lo puramente convencional en una nota bio-bibliográfica. Por lo que se refiere a Lugones, en cambio, apunta el autor en sus palabras lo que ya es un hecho pal pable: la deslumbrante personalidad poética del escritor cordobés, su versatilidad, y asimismo el aire polémico que rodea cada uno de sus actos:

Pocas personalidades tienen hoy entre nosotros contornos tan sobresalientes y relieve tan pronunciado como este distinguido periodista, publicista y poeta.

Su talento y su fecunda labor en el campo de las letras, donde se ha dado a la ímproba tarea de intentar (yendo a campo traviesa) el abrir nuevos caminos para llegar a las alturas del Pindo, no sólo con prescindencia sino también con desdén y menosprecio delo quesu escuela llama viejos formulismos académicos, derrumbando metros, rimas, reglas y artes consagrados, lo ha expuesto a los golpes más violentos de la crítica, pero la ha exhibido con todo el brillo de los entendimientos privilegiados (Puig, vol. X, 1910: XXXVII).

En el mismo año de publicación de la Antología de poetas argentinos, también como parte de los actos conmemorativos del primer Centenario, sale a la luz $O$ das seculares, al gunos de cuyos textos son incluidos en la obra de Puig. No serán pocos los críticos coetáneos que admiren esta obra como una de las máximas expresiones de poesía cívica en línea con las aspiraciones nacionalistas del momento - "una celebración virgiliana de la Argentina", apunta Antonio Pagés Larraya (1968: 135)-. En contraste con el recién publicado Lunario, 0 das seculares marca un cambio de rumbo en la poética 
lugoniana: "Lugones, que cantara el cosmos, los mundos oníricos y literarios, echa pie a tierra y, anteicamente robustecido, inicia con este libro su apego a la realidad argentina, que ampliará en poemarios posteriores" (Barcia, 2000: 18).

M ás allá de la obra de Puig cabe comentar algunas antologías de la segunda década del siglo XX, las cuales muestran en espíritu su filiación respecto a las propuestas nacionalistas del momento y en donde cumple un papel destacado Lugones. En concreto abordaremos tres trabajos: Nuestros poetas jóvenes, de 1911, cuyo autor es Roberto F. Giusti; Nuestro Parnaso, compilado hacia 1913 por el escritor Ernesto M ario Barreda; y la Antología contemporánea de poetas argentinos, cuyos autores son el poeta, crítico y ensayista Ernesto Morales y el también poeta Diego Novillo Quiroga. El primero de los citados trabajos, una antología crítica comentada, surge con motivo de la "despedida" momentánea de Giusti de los círculos críticos y literarios, por lo que la obra se convierte en un emotivo y generoso homenaje a aquellos escritores que durante casi un lustro (1907-1911) pasaron por las páginas de N osotros. Si bien la antología de Giusti, tal y como anuncia el título por extenso, centra su atención en el "actual movimiento poético argentino", el autor dedica un breve capítulo a aquellas figuras de la tradición que han sido relevantes en la evolución de las ideas poéticas en Argentina: Guido y Spano, O bligado, Oyuela. En opinión de Giusti, estos autores mitigaron con sus afanes americanistas el afrancesamiento de la generación romántica. Un afrancesamiento que, en un sentido pendular de la historia, volvería a imponerseen la poesía argentina debido a la influencia simbolista sobre los escritores fin de siglo. Por lo que toca a los poetas que en torno a 1910 forman parte del "actual movimiento" revistado por Giusti -Rojas, Barreda, Banchs, Ghiraldo, Carriego, Arrieta y compañía-, son tenidos por el crítico como los abanderados del cambio, en lo que entiende como una"natural reacción" hacia "una poesía más nuestra, más de la tierra". Además de atender a la tradición y de albergar un buen número de poetas del momento, al gunos ciertamente desconocidos hoy (y desconocidos entonces también por el antólogo, según confiesa), la obra de Giusti presta una especial atención a la figura de Lugones, a la que dedica de forma íntegra un capítuIo: "Leopoldo Lugones" (1911) y un "Apéndice" final (pp. 157-190). Este último reproduce, entre otros textos, un artículo de Giusti sobre el Lunario sentimental en el mismo año de aparición de la obra: "Leopoldo Lugones. A propósito de Lunario sentimental", N osotros, N os 22-23, julio-agosto de $1909^{6}$. Ya en las val oraciones generales con que da comienzo la obra señala Giusti acerca del poeta de Córdoba y su impronta en las letras argentinas:

\footnotetext{
${ }^{6}$ D ebe tenerse en cuenta, pues, quelas opiniones de Giusti sobre Lugones vertidas en N uestros poetas jóvenes están dispuestas en orden inverso: desde las pertenecientes a 1911, año de publicación de la antología crítica, hasta las que aparecen en 1909 en el citado artículo sobre el Lunario.
} 
Desde 1896, Leopoldo Lugones [... ] se ha alzado con la monarquía poética, y desdeentonces su avasalladora retórica ha dominado universal mente, con más o menos vigor, sobre el verso y la prosa de los que han venido después. Nadie ha escapado a tan poderoso influjo literario, ni aun quienes de buena felo niegan. Algunos han llegado más lejos en la sujeción al maestro: decididamente lo han copiado... (Giusti, 1911: 16).

En términos parecidos se expresaba ya en 1909, cuando movido por el asombro ante el estrambótico Lunario sentimental escribía: "La reputación literaria de Lugones diríase definitivamente constituida. Desde la aparición de su primer libro, Las montañas del oro, que le conquistó rápido y ruidoso renombre, el poeta ha compartido con el maestro Rubén la admiración de las jóvenes generaciones, y se ha vuelto blanco predilecto de la imitación más o menos certera de los entusiastas o los pobres de espíritu. Sobre la aceptación del mayor número se ha fundado de esta suerte su pontificado literario" (157). "M onarquía poética", "pontificado literario" son expresiones que remiten específicamenteal lugar de privilegio que ya por estos años ocupa Lugones en el canon de las letras argentinas. M ás allá de las antologías, en 1916 el mexicano Ramón López Velarde publica en Vida M oderna su polémico artículo "La corona y el cetro de Lugones", cuyo título, que casa con la "monarquía poética" de la que nos habla Giusti, no deja lugar a dudas acerca de la dimensión supranacional que ha adquirido el escritor cordobés hacia la segunda década del siglo XX (López Velarde, 1986). En opinión de López Velarde, muerto Darío, Lugones se erige en el poeta canónico por excelencia en el ámbito de las letras hispanoamericanas. La terminología eclesiástica usada por el escritor mexicano nos devuelveel sentido jerárquico de la canonicidad: "Lugones es el poeta sumo. A su lado, todos resultan acólitos. Y si alguien hubiese que con tal apreciación sintiera su prestigio menoscabado, demostraría quesu latín no basta a ayu dar la misa de Lugones" $(480)^{7}$.

Volviendo a Nuestros poetas jóvenes, no obstante los elogios que Giusti dedica a Lugones, el crítico poneigualmentedemanifiesto la“compleja personalidad literaria" que representa el escritor cordobés, matizando así aquellas primeras impresiones de 1909, tras reconocer que eran fruto de sus ím-

\footnotetext{
${ }^{7}$ En su elogio de Lugones, el escritor mexicano llega a colocar a D arío y Lugones en un mismo plano designificación - "ilustres gemel os" Ios llama- , e incluso cuestiona la superioridad del escritor nicaragüense respecto al argentino: "Confieso que viviendo aún Darío, Leopoldo Lugones se me aparecía, a las vegadas, como el más excel so o el más hondo poeta de habla castellana" (López Velarde, 1986: 478). En la edición que García M orales realiza de la obra poética de López Velarde, el crítico sitúa el artículo en cuestión en el contexto cultural mexicano de 1916, donde por entonces tiene lugar una ardua discusión en torno al rumbo que debía tomar la poesía moderna; discusión en la que de forma más o menos velada participan, entre otros, el propio López Velarde y González M artínez, ambos representantes de dos estilos poéticos diferenciados ( García M orales, 2001: 54-56).
} 
petus juveniles. Para cuando Giusti compone la antología, Lugones ha publicado ya cuatro libros de versos, amén de otras obras literarias en prosa y dealgunos ensayos. La mayor crítica expresada por Giusti es la falta de unidad que presenta este corpus, pues cada poemario muestra un Lugones distinto. Admitida esta diversidad, que ya intuyera en su día Darío, e imbuido sin duda del halo de patriotismo que rodea al Centenario, el crítico muestra su preferencia por el Lugones de las 0 das seculares, que tiene su complementario en las escenas en prosa de La guerra gaucha. "Por fin Lugones nos ha dado las lecciones de Belleza y Energía que yo lepedía para poder llamarlo Maestro. No sólo en las 0 das seculares, sino en toda su producción del centenario" (Giusti, 1911: 51). Estas obras conmemorativas, añade el crítico, han hecho olvidar "la orgía de Las montañas del oro", "la afeminación de Los crepúsculos del jardín" y "la locura de Lunario sentimental".

En cuanto al Parnaso de Barreda, publicado en cuatro volúmenes, setrata de una obra de envergadura en donde se recoge una nutrida selección de poesía argentina desde princi pios del siglo XIX hasta el período coetáneo al antólogo, en torno a 1910, en que se dan a conocer en Argentina nuevas voces poéticas que la historiografía literaria suele englobar bajo el nombre de "generación del Centenario" (más genéricamente integrada en el posmodernismo). Una generación que empieza a ser estimada por la crítica literaria del momento, siendo la comentada antología crítica de Giusti un buen ejemplo de ello. Poetas de la talla de Ricardo Rojas, Manuel Gálvez, Arturo Capdevila, Rafael A. Arrieta, M ario Bravo, EnriqueBanchs, Evaristo Carriego, también el propio Barreda, entre otros, todos ellos reunidos en el cuarto y último volumen dela antología. Sin embargo, el antólogo rehúyehacer cualquier valoración crítica de la hora presente, sobre todo por evitar caer en juicios apasionados expresados sin la distancia oportuna.

El tercer tomo dela obra recoge un nutrido grupo de poetas modernistas, la mayor parte de los cuales se incluye en el Parnaso argentino de Pagano. Las valoraciones de Barreda sobre el modernismo finisecular son por lo general positivas, aunque no se declara partidario de "esa tendencia exótica, obra de trasplante, en cuyo exagerado culto todos caímos en un período felizmente corto aunque no muy lejano" (1913, vol. I: 10). Pese a todo, entiende el antólogo (como así lo ha entendido comúnmente la crítica) quea través de la renovación de las letras vía Francia la literatura hispanoamericana sale de su estado de pobreza y se instala en la modernidad estética: "Toda una literatura nueva y no presentida vino a tonificar y enriquecer las arterias de un arte que se moría de inopia, entre el sauzal lloroso de un romanticismo chirle y el seco pinar de un romanticismo venido a menos" (1913, vol. I: 10). Por lo que a Lugones se refiere, señala a modo de laude: "La personalidad de Lugones aparececon perfiles de primera magnitud. [...] Una obra constante, sin decaimientos, nos lo ha presentado en estos últi- 
mos años como un ejemplo para los que desfallecen bajo la inercia del ambiente" (1913, vol. III: 221). En medio de los muchos halagos que recibe el escritor ("habilidísimo", "sutil y exquisito", "retórico prodigioso", “Alí Babá de la palabra"), Barreda lanza un juicio crítico referenteal tono insincero de su poesía, juicio que con el tiempo habrá de convertirse en lugar común de la crítica lugoniana: "Si leo con deleite la poesía de este Alí-Babá de la palabra, su alma de hombre-poeta no me convence" (1913, vol. III: 222). Algunos años más tarde, Borges habría de incidir en la insinceridad de los versos de Lugones, en su falta delirismo y su retoricismo huero, si bien acabará por reconocer en el poeta al gran hacedor de metáforas.

En relación de continuidad con la antología de Barreda, se da a conocer en 1917 la Antología contemporánea de poetas argentinos, cuyos autores son Ernesto M orales y Diego N ovillo Quiroga. "Era una deliberada ampliación de la obra de Barreda, a partir de Lugones", señala Arrieta (1960: 230). En efecto, los autores parten de los mismos presupuestos que el Parnaso de Barreda: dar a conocer la joven poesía argentina, eso sí, esta vez con el ahorro de la tradición antigua (se trata, recordemos, de una antología de poetas contemporáneos) - no obstante, en la "Introducción" puede hallarse un repaso por los distintos períodos históricos- . La obra se divide en dos partes desiguales teniendo en cuenta el número de autores y sus composiciones. En la primera de ellas, la más extensa, se incluyen los poetas modernistas y también los inmediatamente posterioresal modernismo, al gunos de los cuales revelan en sus textos los afanes nacionalistas surgidos en torno al Centenario de 1910. El período contemporáneo, entienden los antólogos, daría comienzo con una figura poética central: Leopoldo Lugones. El es el presente y es también la esperanza de futuro, asegurado en el ejercicio de su liderazgo para con las jóvenes generaciones, a las que se exhorta sin embargo a buscar su voz más personal e íntima. En cualquier caso, la relevancia que conceden ambos autores a la figura de Lugones como iniciador de la poesía argentina contemporánea pasa desapercibida en la obra, dada la ordenación alfabética - un tanto asistemática, hay que decir- de los autores seleccionados (de ahí la necesidad imperiosa de la "Introducción" en su función orientadora).

\section{LOSAÑOS 20: LUGONESEN EL CENTRO DEL CANON}

La publicación en 1926 de la Antología de la poesía argentina moderna de Julio Noé, y su posterior edición de 1931, con al gunos cambios significativos, marcará un antes y un después en la práctica antológica de ámbito hispánico, convirtiéndose de inmediato en una obra de referencia inexcusable para ulteriores trabajos de antologación dentro y fuera de Argentina. La antología deN oées, ante todo, el resultado deuna tarea ambiciosa por parte 


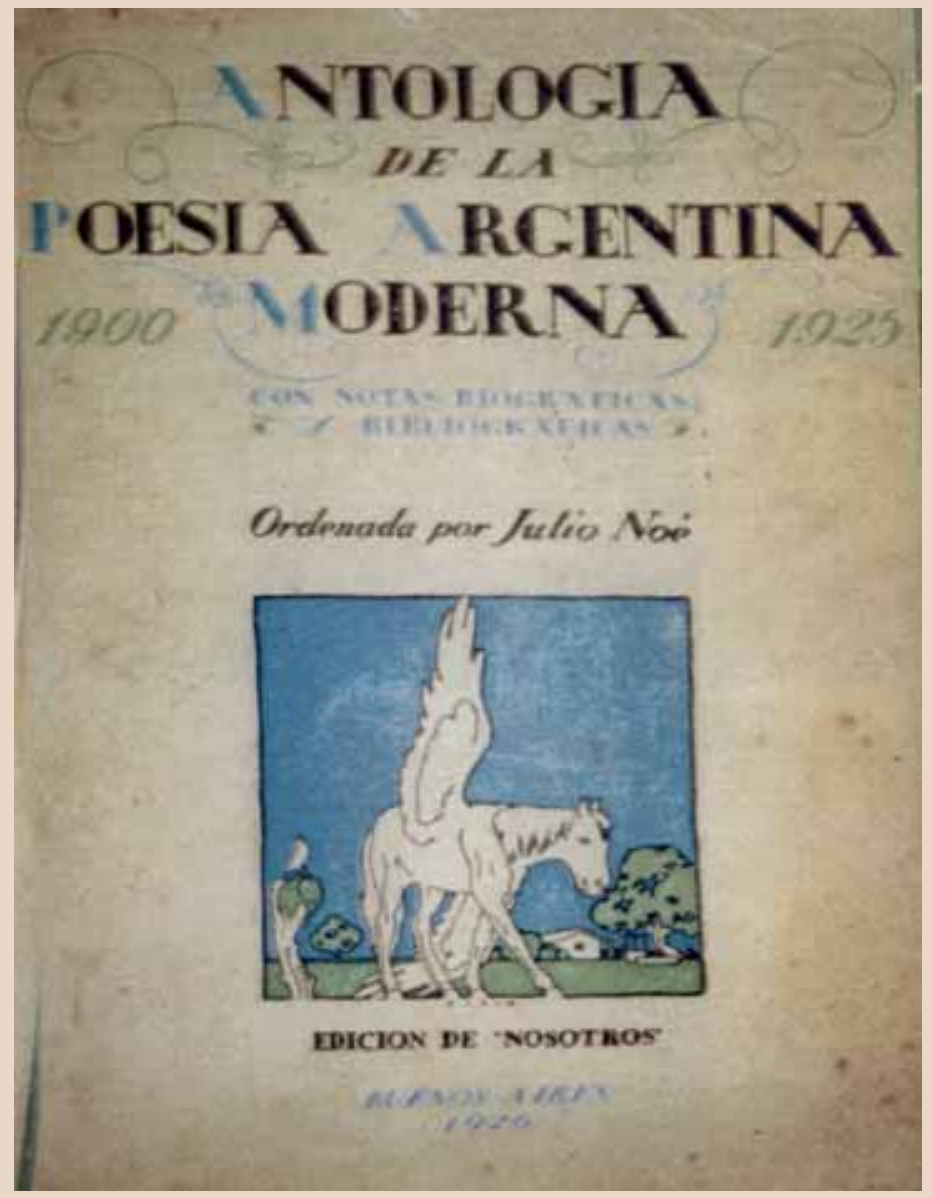

de un lector y crítico de gran calibre, cuya relevancia y participación en los medios socioculturales bonaerenses durante la primera mitad del siglo XX fue más que notoria. La presentación y estructuración cronológica de la selección nos da idea del modo en que Noé contempla la evolución de la moderna poesía argentina, sus autores claves, los grupos culturales más destacados, los períodos representativos. El corte de inicio lo marcan los poetas modernistas cuya obra poética ve la luz a principios del siglo XX, por lo que no aparecen recogidas al gunas figuras anunciadoras dela modernidad poé tica: Almafuerte, O bligado, Oyuela, Leopoldo Díaz, aunque hayan publicado en el mencionado siglo. Teniendo en cuenta este criterio arbitrario, los autores seleccionados quedan repartidos del siguiente modo:

Ocupa la primera parte Leopoldo Lugones, la personalidad más fuerteentre los jóvenes poetas de los comienzos de esta centuria, y que al fenecer el pe- 
ríodo abarcado por esta antología, sigue siendo, como en sus años mozos, duramente discutido, después de haber influenciado a muchos de los autores aquí representados. La segunda parte ha sido destinada a los poetas que comenzaron su obra a fines del siglo pasado o primeros años del nuestro. La tercera a los que se iniciaron después de 1907, año de la aparición de Enrique Banchs y de la revista "Nosotros", denunciadores de un estado nuevo de la cultura argentina. En la última parte figuran los poetas más jóvenes y los que expresan una novísima orientación del gusto y de las normas poéticas (Noé, 1926: 6-7).

Pedro Henríquez Ureña ha descrito la estructura de la obra "como torre de cuatro cuerpos, donde la figura atlántea de Lugones constituye sola el primero y sostiene los tres superiores" (1926: 271). N oé no sólo ve en él a uno de los grandes impulsores del modernismo argentino, heredero directo deDarío; más importantesi cabe-lo reafirma décadas más tarde en el tomo IV de la H istoria deArrieta-, admira su capacidad de superación de la estética finisecular más preciosista y decadente con su propuesta de temas argentinos hacia la década del 20 (Noé, 1960: 66). Una propuesta que posee un claro trasfondo ideológico y una finalidad social bien definida. En línea con sus planteamientos nacionalistas, la obra ensayística y poética de Lugones está concebida desde una funcionalidad docente 8 . O das seculares (1910), EI payador (1916), los Estudios helénicosI y II (1922-1923), El libro delos paisajes (1917), Las horas doradas (1922) o Poemas solariegos (1928), entre otros textos, no son sino piezas de un engranaje mayor que persigue ante todo la educación del pueblo en el pasado más glorioso y en las costumbres propias. Constituyen, dicho en otras palabras, la búsqueda de una identidad argentina capaz de integrar a esa vasta población foránea que invade las ciudades. Este proyecto educacional que va urdiendo Lugones a lo largo de su vida y obra encuentra su mejor cauce en la presentación estética de las ideas, esto es: la poesía, con un sentido homérico en lo que se refiere a su función social’." "Lugones consideró la educación estética como la mejor formación humana. El había percibido con claridad que la estética constituye la mejor iniciación filosófica; de ahí que le atribuyera tan grande valor formativo, derivado, como es natural, dela función social del arte" (Tello, 1971: 114).

La declarada función cívica y social (patriótica, en definitiva) de la poesía de Lugones, acentuada a partir de 1910, es a buen seguro la que coloca al

8“Lugones nunca sedesentendió totalmentedecierta preocupación docente-nos diceBelisario Tello-, por considerarla inseparable de su construcción política, en la cual efectivamente se integra; pues su filosofía pedagógica es inexplicable sin su teoría del Estado" (1971: 114).

"Juan Carlos Ghiano señala que la categoría de "social" puede extenderse a toda la obra poética lugoniana (y ensayística, habría que añadir), desde sus comienzos finiseculares hasta los Romances de Río Seco publicados de forma póstuma en 1938 (1978: 77). 
escritor a la cabecera de algunos proyectos antológicos publicados en los años 20, trabajos que muestran abiertamente una filiación nacionalista en lo referentea la búsqueda delo propio argentino. Es el caso del N uevo Parnaso publicado por Maucci en 1927, obra de Valentín de Pedro que supone una puesta al día del Parnaso argentino de Pagano. De inicio, el antólogo defiende en el "Prólogo" la novedad de su trabajo y aclara que el Nuevo Parnaso argentino no es una mera reedición corregida y aumentada del Parnaso de 1904, sino otra obra, necesariamente distinta, pues distintos son el tiempo que refleja y el autor que realiza la labor de compilación. Siguiendo esta lógica, pocos son los poetas que el antólogo rescata de la obra de Pagano para su Nuevo Parnaso. Pero entre ellos, como si de un obligado cumplimiento se tratara (¿el peso ineludible dela canonicidad?), seencuentra Lugones, quien abre la antología (los autores aparecen ordenados por orden cronológico, atendiendo así a un principio historiográfico). Una ubicación privilegiada queno deberesultar extrañasi tenemos en cuenta el lugar dehonor que por estos mismos años ostenta en otras antologías aledañas, como la ya tratada de Noé y alguna otra posterior que más adelante comentaremos. Curiosamente, Lugones aparece situado por delante de Almafuerte, pese a que éste nace dos décadas antes que el poeta cordobés (Lugones nace en 1874); e igual mente desplaza a Carlos Ortiz, quien nace en 1870. Heaquí uno delos amaños cronológicos quehaceel antólogo, seguramenteforzado por el mayor peso canónico que representa Lugones por entonces.

La partenuclear dela antología la constituyen los poetas posmodernistas con una presencia literaria destacada a tenor del número de composiciones que de cada uno se incluye, lo que equipara cuantitativamente a estos autores con la importancia inaugural concedida a Lugones. Este dato contrasta claramente con la ausencia de los poetas modernistas que rodearon a Darío en el fin de siglo, exclusión que De Pedro explica argumentando que ninguno de estos autores presenta rasgos de renovación poética, pues han quedado estancados en el declive modernista. Aquellos herederos argentinos dela poética rubendariana, al gunos de los cual es serecogen en el Parnaso de 1904, poco responden a losintereses que persigueD e Pedro en su antología, transcurridos más de veinte años. Frentea los poetas finiseculares deslumbrados por París, el antólogo prefiere a esos otros escritores, más nuevos, que en las dos primeras décadas del siglo XX se muestran "saturados de ambiente, impregnados de tierra" (1927: 6). Se entiende de este modo que encabecen la antología dos autores como Lugones y Carlos Ortiz: el Lugones de las $O$ das seculares en honor a la patria y los paisajes de provincia, quien en los años 20, a contrapelo de la joven vanguardia, constituye un paradigma de la poesía cívica y nacionalista en Argentina; y el Carlos O rtiz del Poema de las mieses (1902) - no el de Las rosas del crepúsculo (1899)- , que posee"el acierto del tema, y la virtud de buscar en su propia tierra losmotivos desu inspiración" (29). 


\section{LUGONESY LA JOVEN VANGUARDIA: LA CONTROVERSIA DEL "MAESTRO"}

Lejos de lo que a priori pudiera pensarse, las antologías poéticas aparecidas en los años 20 apenas se hacen eco del movimiento de renovación que, acicateado por los ismos europeos, comienza a asomar en Argentina a principios dela década. Lo cual hasta cierto punto podría ser comprensibleen el caso del Nuevo Parnaso argentino de J. E. Gramajo, que ve la luz en 1922, fecha esta que viene a coincidir con los primeros brotes vanguardistas ${ }^{10}$. M enos lógico parece en el caso de las dos antologías anteriormente comentadas, las de Noé y De Pedro, publicadas en 1926 y 1927 respectivamente, unos años en que ya han tenido lugar algunas transformaciones poéticas significativas provenientes del núcleo marfierrista. No obstante, si bien al hilo de lo sucedido en Europa se ha querido presentar los años 20 como un período transgresor en lo que al arte hispanoamericano en general se refiere, no son pocos los juicios de época que contradicen esta lectura en el caso particular de Argentina (curiosamente uno de los países que encabeza el aperturismo vanguardista en la América Latina). "Si se considera con desapasionamiento la sucesión de las modas y escuelas literarias - afirma Julio Noé- y se inquiere sobrelo esencial y profundo que distinguelas unas delas otras, concluiríamos por dar muy escasa trascendencia al movimiento de renovación comenzado en 1922" (en Vignale y Tiempo, 1927: VI). Por su parte, Evar M éndez señala también en 1927:

Las audacias de nuestros poetas nuevos -y esto no es en desmedro de ellosno van demasiado lejos en cuanto a forma, a escritura: nada de anarquismo, confusión, nihilismo. Aquí no sehacen caligramas, no tienen mayor fortuna los poemas en varios planos o para varias voces (también aquí ensayados), ni seduce ninguna construcción poético-tipográfica, tan abundantes en todas partes [... ]. Ninguna locura, ninguna desmedida fantasía, nada de dadaísmo 0 antiliteratura disolvente, ni siquiera dejar hablar al subconsciente: aún no ha hecho camino el superrealismo aquí (en M endiola Oñate, 2001: 115) ${ }^{11}$.

Por lo que corresponde a las antologías, la desatención manifiesta hacia el movimiento martinfierrista que dejan entrever los diversos trabajos publicados en los años 20 encuentra su más genuina contestación en la Exposición de la actual poesía argentina (1927), la antología vanguardista por excelencia, que compilan dos poetas del momento: Pedro Juan Vignale y Cé-

${ }^{10}$ Sin embargo, no es esta la verdadera razón por la cual no aparecen los poetas de la hora recogidos en esta antología, sino, tal y como el propio antólogo explica, por pura cuestión de espacio.

${ }^{11}$ Se trata de un artículo que lleva por título "Doce poetas nuevos", publicado en Síntesis, Buenos Aires, año I, № 4, septiembre de 1927. 


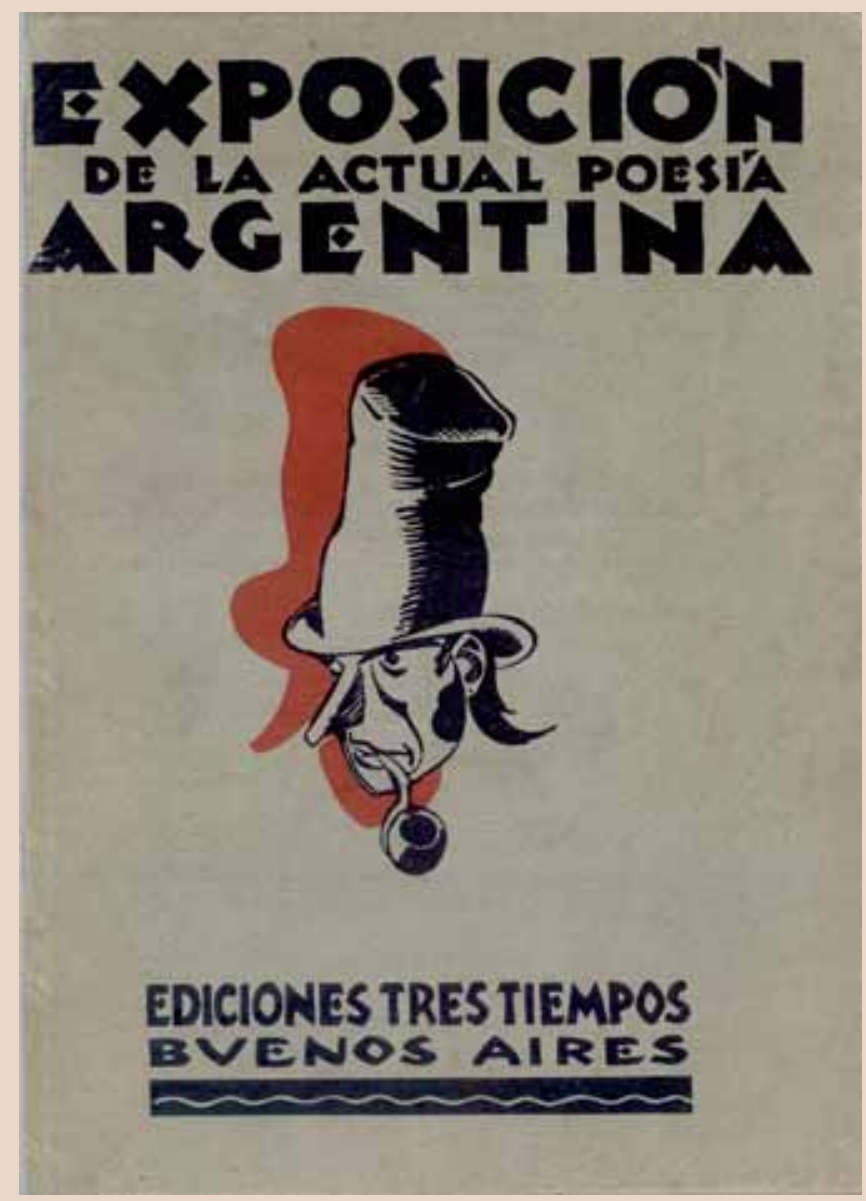

sar Tiempo. La Exposición es, entre otras muchas cosas, una muestra panorámica de la joven poesía argentina que se da a conocer entre 1922 y 1927, justamentelos años de mayor actividad vanguardista a nivel degrupo(s). La obra se inicia con una serie de textos críticos que funcionan como una obertura polifónica, verdadero diálogo polémico minado de referencias que no dejó indiferentes a quienes por entonces participaban en las encendidas disputas culturales con telón político. La serie se abre con Leopoldo Lugones ("Estética") y continúa con Rafael de Diego ("Paralelo"), Julio Noé("19071922"), Ricardo Güiraldes( "Poesía"), TomásAllendel ragorri ("Quéentiendo por poesía lírica"), Roberto M ariani ("La extrema izquierda") y finalmente Evar M éndez ("Rol de M artín Fierro en la renovación poética actual"). Qué duda cabe que dar comienzo con un texto programático de Lugones aseguraba en aquel contexto un debate encendido, como ha señalado oportunamente Cansinos Assens: 
Ese trozo dogmático de Lugones, sólo parece colocado liminarmente en esta Exposición para que otros teorizantes juveniles se den el gusto de contradecirlo y de contradecirse también en breves manifiestos doctrinales o resúmenes literarios [...]. En general, puede advertirse la timidez con que las generaciones nuevas tienden a emanciparse del prestigio de Lugones, que aún conserva la autoridad que le confiere una obra vasta einteresante (1998: 675-676).

Sabedor del lugar oportunísimo que ocupa en la platea, el escritor cordobés aprovecha su panfleto para lanzar una serie de diatribas contra aqueIlos poetas vanguardistas quetanto habían criticado su modo deentender la poesía y que practicaban impunemente el prosaísmo poético: "Amontonar imágenes inconexas en parrafitos tropezados como la tos, y desde luego sin rima; he ahí toda la poesía y todo el arte" (en Vignaley Tiempo, 1927: i-ii). Según entiende Lugones en lo que viene a ser uno de sus principales dogmas poéticos, cuando el verso prescinde de la rima, que es su esencia, se convierteen un simple"renglón de prosa". Frentea esta preceptivalugoniana, los poetas vanguardistas proclamarán en al to el verso libre absuelto de toda rima. En un artículo publicado en M artín Fierro, Leopoldo M arechal realiza una defensa del versolibrismo y desmonta uno a uno los fundamentos poéticos de su "tocayo y maestro": "La rima es un opio barato que se administra al lector, para adormecerleanteel contenido esencial del poema. La mayoría de los poemas rimados hacen el efecto de esas bandas municipales, cuyo exceso de bombo y platillo sofoca lo más precioso de la obra" (1925: 2). A través de diversas revistas, uno y otro escritor se enzarzarán en una disputa que llega a alcanzar un tono elevado. Pasado el tiempo, al ser preguntado $M$ arechal por las relaciones entre Lugones y los martinfierristas en los años 20, señal ará: "Siempretuve muy serias razones intelectuales y humanas para no querer a mi tocayo. El representa para mí todo lo que no me gustaba ni me gusta en nuestra desdichada República: la ciega y jamás caritativa exaltación del 'ego', la 'inautenticidad' y la 'irresponsabilidad' intelectuales". A lo que añade: "Lugones estuvo en el polo contrario de nuestro movimiento martinfierrista y de la conciencia de sus mantenedores" (en Fernández M oreno, 1977: 43-44). Hay que decir sin embargo que Lugones no estuvo solo en su crítica a la nueva poesía que representa la juventud de vanguardia. Por parte de ciertos sectores de la crítica, sobre todo de aquellos que, como el poeta de Córdoba, seguirán defendiendo una concepción decimonónica de la poesía, se rechazan los nuevos modos por representar éstos el "mal gusto" literario. "H ay que reconocer una novedad en este movimiento en nuestro país, y es esa intercalación de imágenes de dudoso buen gusto, tanto que se podría escribir un ensayo titulado El mal gusto en la literatura argentina" (Aita, 1930: 73). 
Más allá de toda disputa, el hecho innegablees que hacia la década del 20 Lugones se había convertido en una referencia inexcusable (insalvable, se diría) en el ámbito cultural y político de Argentina. La canonización del escritor de Córdoba es, desde esos años, un hecho irrefutable, como bien demuestra el lugar de honor que ostenta en las antologías poéticas del momento. En estesentido, la Exposición deVignaley Tiempo no hacesino afianzar la figura del poeta cordobés como "maestro" y "guía", o cuando menos como punto de arranque del debate sobre las ideas estéticas. Considerado como el gran iniciador de la modernidad poética en Argentina; heredero directo de las enseñanzas de Darío y valuarte indiscutible del movimiento modernista con centro en Buenos Aires; y al mismo tiempo anunciador de lo que vendrá después, Lugones se instala definitivamente en el canon poé tico nacional como piedra angular sobre la que se construyela modernidad literaria y referencia ineludiblea nivel continental, no sólo en lo tocante ala literatura sino del mismo modo al pensamiento crítico. En este orden de cosas, no debe verse como un hecho casual queal fundarse en 1928 la Sociedad Argentina de Escritores sea nombrado Lugones primer presidente de dicha institución. Era, como poco, el reconocimiento de una autoridad, la institución del escritor como cabeza visible de una nueva especie intelectual.

\section{LEOPOLDO LUGONES, MONUMENTO NACIONAL}

En los años que transcurren de 1928 a 1938, la última década en la vida del escritor, las antologías de poesía argentina añaden poca cosa a la imagen consolidada de Lugones que proyectan los años 20. La producción antológica referida a la poesía argentina va a seguir siendo muy abundante en la década del 30, si bien es cierto que la crítica ha prestado mucha menos atención a los trabajos realizados en este período. Entrelo más destacado de estos años, amén de la Antología de la poesía femenina argentina (1930) de Maubé y Capdevielle, cabe mencionar algunas compilaciones en las que al mismo tiempo que se muestra el rechazo de la poesía inmediata anterior (la que realiza la llamada "generación de 1922") se proponen nuevos postulados como salida a la estética de vanguardia. La novísima poesía argentina (1931) de Cambours O campo y la Vidriera de la última poesía argentina (1937) de Andrés del Pozo son obras significativas al respecto, la primera de las cuales suscita entrela crítica un encendido debategeneracional. Sin embargo, concentradas ambas en la actualidad del momento, ni una ni otra ofrecen una mirada hacia el pasado, por lo que su valor historiográfico es limitado. M ucho más relevante resulta el Indice de la poesía argentina contemporánea 


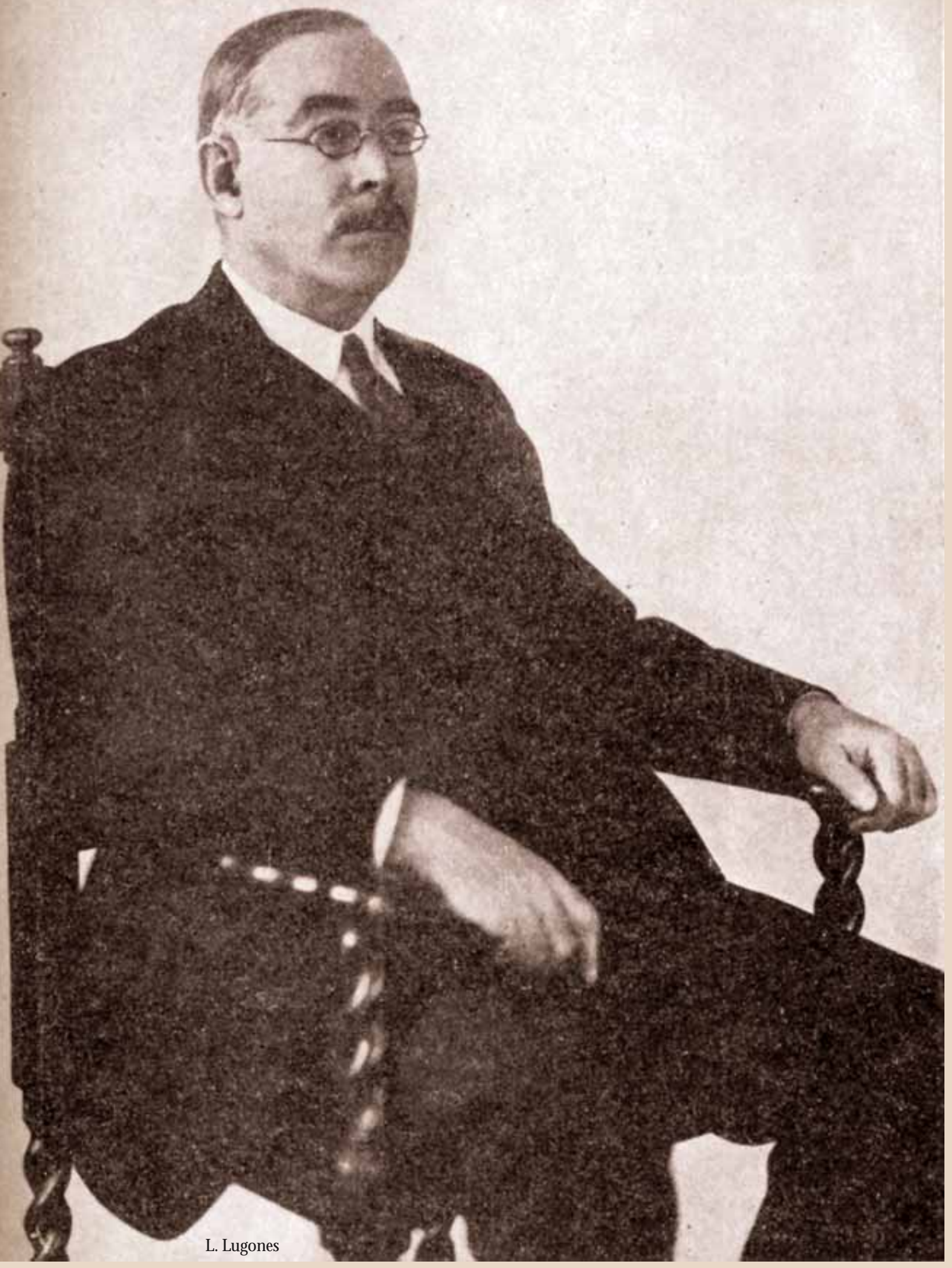


(1937) compuesto por el poeta y ensayista José González-Carbalho ${ }^{12}$. Para la elaboración de este Indice, el antólogo tendrá muy en cuenta la tradición de antologías poéticas modernas en Argentina, fundamentalmente las de Noé y Vignale-Tiempo. Al igual que sucede en otros trabajos predecesores, es Lugones quien encabeza la obra, integrando la primera de las cuatro partes que conforman el Indice, junto con dos poetas nacidos en la década del 80: Enrique Banchs y Evaristo Carriego. "Indiscutible-aunque, con justicia, nos moleste confesarlo- es la autoridad de Lugones como maestro sobre algún poeta contemporáneo, que asimiló en forma tal esa influencia, que llegó a convertirla en el más generoso aspecto de su personalidad" (1937: XI). A diferencia de Noé, González-Carbalho no incluye en su Indice a ninguno de los poetas modernistas que seguían publicando a comienzos del siglo XX, salvo Lugones, quien por otra parte aparece más en calidad de orientador de las nuevas generaciones que como poeta fin de siglo. A este respecto debe recordarse las distintas miras de una y otra obra: la de Noése anuncia como una antología de poesía argentina moderna, mientras que el Indice de González-Carbalho se centra más concretamente en el período contemporáneo, cuyo comienzo fija el antólogo a partir de 1900. Curiosamente, Noéarranca de esta misma fecha para señalar el comienzo dela poesía moderna en Argentina; en la edición de 1931, en cambio, retrasará el margen temporal hasta 1896.

En 1938 tiene lugar la tragedia de Isla del Tigre: Lugones se suicida para sorpresa y espasmo de todos. La noticia afectó muy hondamente a la clase intelectual argentina, según testimonios de época. Sin entrar aquí en las verdaderas causas de este fatal suceso, que resultan complejas por las implicaciones con la vida personal del escritor y con los destinos de la nación ("Tú, destructora tierra: tú misma le has matado", escribirá Larreta), lo cierto es que aquella muerte antinatura sirvió de freno a las opiniones desmedidas que en grado negativo, y paralelamente al reconocimiento puntual de su obra, se fueron vertiendo sobre el hombre político a lo largo de los años 2030. Quedaban así difuminados los desmedidosal egatos filonacionalistas del escritor y su relación con el golpe militar de 1930, en el que cumplió un papel relevante. Una autoridad como Borges, quien en su juventud había atacado a Lugones duramente tachándolo de patriótico fascista, acabaría por reconocer su magisterio sobre la joven generación de vanguardia; más aún, terminará viendo en él a un claro precursor de su propia obra. En la Antología poética argentina (1941) que Borges realiza junto con Bioy Casaresy Silvina 0 campo, puedeleerse esta sentencia indudablemente borgesiana que aparece en el "Prólogo": "No es imposible que los críticos de un porve-

\footnotetext{
${ }^{12}$ Esta obra forma parte de una serie de "Indices poéticos" proyectados por la editorial chilena Ercilla, cuya primera entrega está centrada en la poesía uruguaya contemporánea que compila y presenta el crítico y ensayista Alberto Zum Felde.
} 
nir remoto juzguen que todos los poetas actuales son facetas o hipóstasis de Lugones" (1941: 8). De forma matizada, ello había sido ya señalado por Borges en vida de Lugones -en realidad muy poco antes de su muerte, en 1937-, en un conocido artículo que lleva por título "Las'nuevas generaciones' literarias" (Borges, 1997: 497-499) ${ }^{13}$. En él, Borges se inscribe entre los poetas lugonianos, autoproclamándose (bajo el arropo de su generación) beneficiario directo de la herencia del maestro, en lo que viene a ser una maniobra de validación de la poética de ciudad que define su poesía de los años 20, así como la de algunos compañeros de generación: Girondo, Güiraldes, Francisco Luis Bernárdez. "Examine el incrédulo lector el Lunario sentimental, examine después los Veinte poemas para ser leídos en el tranvía o mi Fervor de Buenos Aires o Alcándara, y no percibirá la transición de un clima a otro" (Borges, 1997: 499). Respecto a este intencionado posicionamiento que lleva a cabo Borges dentro del campo cultural argentino, Leopoldo $\mathrm{M}$ arechal señala mordazmente: "D espués de haberlo ridiculizado tanto, [Borges] convirtió a Lugones en una suerte de pater familias de toda nuestra literatura, en otras de las mistificaciones literarias a las que tan aficionado es y en las que generalmente George trabaja pro domo sua" (en Fernández M oreno, 1977: 45). Esta exaltación de Lugones se verá continuada en torno a los años 60, cuando Borges ve llegada la hora de ordenar su propia obra, esbozando para tal fin una imagen de escritor que se instalará por mucho tiempo (más allá incluso de su propia muerte) en la historia literaria argentina. Tal vez más que nunca, pues necesita autorizar sus comienzos literarios, Borges encomia la figura de Lugones se diría que obsesivamente, rindiendo pleitesía a una labor poética de la que dice sentirse poderosamente influenciado ${ }^{14}$. En uno de los textos que integran el ya citado ensayo Leopoldo Lugones, Borges comienza diciendo: "Decir que ha muerto el primer escritor de nuestra república, decir que ha muerto el primer escritor de nuestro idioma, es decir la verdad y es decir muy poco" (1997:

\footnotetext{
${ }^{13} \mathrm{El}$ texto aparece publicado originariamente en la revista El Hogar el 26 de febrero de 1937. Posteriormentefueincluido en el ensayo queBorges dedica a Lugonesen colaboración con Betina Edelberg: Leopoldo Lugones (1965), en Borges (1997: 497-499). Cabe advertir que la fecha de publicación de Leopoldo Lugones que aparece en las 0 bras completas, 1965, se refiere a la segunda edición (Buenos Aires, Pleamar, 114 pp.); la primera edición del ensayo ve la luz en 1955 (Buenos Aires, Troquel, $99 \mathrm{pp}$.).

${ }^{14}$ Para entonces el abrazo de los dos titanes era un hecho imposible. Borges, sin embargo, lo inventa para creerlo real. Sucedeen 1960, en el prólogo a El hacedor queBorges dedica “A Leopoldo Lugones". Allí recrea el autor un encuentro ficticio con un anciano Lugones. El discípulo (Borges) va a la casa del maestro (Lugones) y le muestra su obra -El hacedor- buscando su aprobación: "Si no me engaño, usted no me malquería, Lugones, y le hubiera gustado quele gustara al gún trabajo mío. Ello no ocurrió nunca, pero esta vez usted vuelve las páginas y lee con aprobación algún verso, acaso porque en él ha reconocido su propia voz..." (Borges, 1989: 157).
} 
500) ${ }^{15}$. Una opinión que ratifica hacia 1965, al afirmar de forma categórica: "Leopoldo Lugones fue y siguesiendo el máximo escritor argentino" (1997: 507). Se refiere con ello, si atendemos a las matizaciones que siguen a esta frase, a Lugones como obra total, hecho que incluye la propia vida del escritor como parte de su opera omnia. En opinión de Borges, todo escritor crea dos obras fundamentales: sus escritos y la imagen de sí mismo, y ambas se entreveran y contaminan de forma irremediable.

M ás allá de Borges, el estatus alcanzado por Lugones en los años veinte encontrará su eco en otras valoraciones que nos muestra la historiografía literaria argentina. En el ya citado ensayo sobrela moderna poesía argentina que se incluye en el IV tomo de la reputada Historia de Arrieta, Julio Noé viene a reafirmarse en sus posiciones de 1926 y 1931 al conceder al escritor un lugar central en la historia de las letras nacionales: "No es posible tratar de la poesía argentina de la primera mitad de esta centuria sin referirse a su personalidad vigorosa, nunca descuidada por las varias generaciones de poetas que en esas cinco décadas se han sucedido entre nosotros. Con él o contra él han estado casi todos; con ellos o contra ellos también estuvo Lugones" (Noé, 1960: 66). Por su parte, Emilio Carilla señala en Estudios de literatura argentina: "Leopoldo Lugones es al go así como el nombre claveen las aproximaciones y diferencias. Pero la situación de Lugones es perfectamente comprensiblesi tenemos en cuenta lo que significó en nuestra literatura. Fobias y filias a un lado, ningún otro escritor argentino tuvo en lo que va del siglo su dimensión y resonancia". Y añade enseguida: "Evidentemente, Lugones ocupa un lugar singularísimo (en el que no siempre tiene que ver el valor desu obra) dentro de las letras argentinas, lugar que, más allá de generaciones y escuelas, mantuvo hasta el instante de su muerte. De su forma posterior, baste con decir que la dimensión ha crecido" (1968: 62-63). Estas y otras declaraciones similares ofrecen pocas dudas respecto a la posición central que ostenta Lugones en la historiografía argentina, sobre todo en tanto que eje sobreel que giran los distintos procesos de transformación que en el ámbito de la estética tienen lugar entre 1900-193016. Amparada

${ }^{15}$ El ensayo Leopoldo Lugones, aunque publicado en 1955 , se compone de textos pertenecientes a distintos años, desde los años 30 a los 60 . En concreto este que citamos está escrito en la inmediatez de la fatal muerte del escritor en febrero de 1938 ("Leopoldo Lugones", Sur, Buenos Aires, año VIII , № 41, febrero de 1938; poco después sería publicado en Nosotros, BuenosAires, $2^{\text {a }}$ época, año 3, № 26-28, mayo-julio de 1938. En el texto original, el uso distinto de los tiempos verbales revela la inmediatez del hecho: "Decir que acaba de morir el primer escritor de nuestra república..."). El hecho significativo es que Borges valida esta afirmación categórica al revisar las sucesivas ediciones de Leopoldo Lugones publicadas en 1955 y 1965.

${ }^{16}$ Borges llega incluso a ampliar este radio designificación y central idad al sugerir quea partir de Lugones puede explicarse to do el pasado y el futuro de las letras argentinas, de dónde vieney hacia dónde va. "Juzgarlo es juzgar a mi generación y acaso a toda la literatura argentina" (1997: 505). 
por la realidad antológica, la historiografía más actual nos muestra a un Lugones fundador de la modernidad literaria en Argentina y también al escritor totalizanteen su afán de abrir nuevos caminos estéticos de ida y vuelta, que vistos en su conjunto dibujan un raro y caprichoso itinerario.

Con todo lo expuesto, es mucho desde luego lo que queda por decir sobre Lugones. Ni siquiera a fecha de hoy contamos con una biografía medianamente respetable del escritor ${ }^{17}$ - en su caso muy necesaria, siendo como ha sido "el menos autobiográfico de nuestros poetas", nos recuerda M astronardi-, y la lejanía de las conmemoraciones no augura ninguna sorpresa en este sentido, como no las hubo por cierto en el primer centenario de su nacimiento. "La totalidad, muy probablemente, no es conocible, ni la satisfacción de un conocimiento completo y acabado", nos advierteClaudio Guillén siguiendo a Edgar Morin (1998: 29). De ahí que todo esfuerzo resulte insatisfactorio si no se entiende como un proceso gradual y continuado de acercamiento al objeto de estudio. En el caso particular de Lugones, resulta ciertamente difícil captar en un puñado de páginas la totalidad de un escritor que en sí mismo representa una totalidad, una summa. Tan sólo me he limitado aquí a señalar un aspecto en concreto de entre los muchos posibles que pueden y deben abordarse desde nuevas perspectivas: la imagen que las antologías poéticas argentinas proyectan de Lugones en un período clave de las letras argentinas. Un aspecto que no en vano se muestra revelador por cuanto que, tal y como se dijo al comienzo, las antologías cumplen una función canonizadora dentro de un espectro cultural concreto, en concomitancia con la historia literaria. En este sentido, queda suficientemente demostrada la preponderancia de Lugones en el panorama de las antologías poéticas argentinas publicadas en las primeras décadas del siglo $X X, y$ asimismo la proyección de este hecho en la historiografía literaria. Fuera de toda discusión canónica parece estar el hecho de que, dentro y fuera de la poesía, a nadie dejó indiferente Lugones entre sus contemporáneos, lo que ciertamente dificulta un juicio que comprometa sólo a la poesía y al poeta. "Tres generaciones se preguntaron: ¿Q ué piensa Lugones de esto? ¿Qué dice Lugones de aquello? En cualquier discusión sobre arte, política o ciencia, sus opiniones suscitaban la controversia. Interesó el fondo ideológico de sus definiciones. Su rebeldía literaria y su rebeldía intelectual no podían provocar consensos unánimes" (1968: 32).

${ }^{17}$ Además de la ya citada biografía que escribe su hijo, poco rigurosa en el plano de lo ideológico y lo literario, como se enten derá, cabe mencionar, entrelos muchos monográficos dedicados al escritor, los acercamientos ensayados por M artínez Estrada (1968) y Capdevila (1973), obra esta última que adolece decontaminaciones subjetivas-las recreaciones dialogadas son un buen ejemplo de ello- , en tanto que está escrita desde el fervor de la amistad y desde la admiración intelectual que el autor profesa al escritor cordobés. 


\section{REFERENCIAS}

Aita, Antonio. 1930. Algunos aspectos de la literatura argentina. Buenos Aires: Nosotros.

Arrieta, Rafael Alberto. 1960. "Cancioneros patrióticos y antologías", en Rafael Alberto Arrieta (ed.), Historia de la literatura argentina, tomo IV. Buenos Aires: Peuser, pp. 203-237.

Barcia, Pedro Luis. 2000. “La celebración poética de la patria”, estudio preliminar de O das seculares (1910), en Lugones, Leopoldo, O bras completas, tomo III. Buenos Aires: Pasco.

Barreda, Ernesto M ario. 1913. Nuestro Parnaso. Colección de poesías argentinas, 4 vols. Buenos Aires: Juan L. Dasso y Cía.

Borges, Jorge Luis. 1989. O bras completas, tomo II. Barcelona: Emecé.

Borges, Jorge Luis. 1997. O bras completas en colaboración. Barcelona: Emecé.

Borges, Jorge Luis, O campo, Silvina y Bioy Casares, Adolfo, 1941. Antología poética argentina. Buenos Aires: Sudamericana.

Cansinos Assens, Rafael. 1998. “La evolución dela poesía argentina. Del M odernismo al Ultraísmo", La nueva literatura. Tercera parte: La evolución de la poesía (1917-1927) (1927), en Obra crítica, vol. I. Sevilla: Diputación de Sevilla, pp. 647-710.

Capdevila, Arturo. 1973. Lugones. Buenos Aires: Aguilar.

Carilla, Emilio. 1968. "El vanguardismo en la Argentina", en Estudios de literatura argentina (SigloXX). Tucumán: Universidad Nacional de Tucumán, pp. 61-103.

Cella, Susana. 1998. "Canon y otras cuestiones", en Cella, Susana (ed.), Dominios de Ia literatura. Acerca del canon. Buenos Aires: Losada, pp. 7-16.

Darío, Rubén. 1950a. "Cabezas: Leopoldo Lugones", M undial, París, noviembre de 1911, p. 35, en 0 bras completas, tomo II. M adrid: Afrodisio Aguado, pp. 990993.

Darío, Rubén. 1950b. Autobiografía (1912), en O bras completas, tomo I. M adrid: Afrodisio Aguado, pp. 17-177.

Fernández M oreno, César. 1977. "Distinguir para entender (Entrevista con Leopoldo M arechal)", en Collazos, Oscar (ed.), Los vanguardismos en la América Latina, Barcelona: Península, pp. 41-48.

García M orales, Alfonso. 1998. “Construyendo el modernismo hispanoamericano: Rubén Darío y Carlos Romagosa”, en García Morales, Alfonso (ed.), Rubén D arío. Estudios en el Centenario de "Los raros" y "Prosas profanas". Sevilla: Universidad de Sevilla, pp. 85-114.

García M orales, Alfonso. 2001. “Ramón López Velarde y el mito del poeta nacional de M éxico", introducción a López Velarde, Ramón, La sangre devota. Zozobra. El son del corazón. Madrid: Hiperión, pp. 9-99.

Ghiano, Juan Carlos. 1978. "Para una biografía de Lugones", en Relecturas argentinas. Dejosé H ernández a Alberto Girri. Buenos Aires: El Mar deSolís, pp. 71-80.

Giusti, Roberto F. 1911. Nuestros poetas jóvenes. Revista crítica del actual movimiento poético argentino. Buenos Aires: Albasio y Cía., N osotros.

González-Carbalho, José. 1937. Indicedela poesía argentina contemporánea. Santiago de Chile: Ercilla, "Biblioteca América”. 
Gramajo, J. E. 1922. Nuevo Parnaso argentino. Selecta colección de poesías de los mejores poetas nacionales, antiguos y modernos. Buenos Aires: M aucci $\mathrm{H}$ nos.

Guillén, Claudio. 1998. M últiplesmoradas. Ensayo deliteratura comparada. Barcelona: Tusquets.

Henríquez Ureña, Pedro. 1926. “Poesía argentina contemporánea”, en Valoraciones, tomo 3, marzo, pp. 270-274.

López Velarde, Ramón. 1986. "La corona y el cetro de Lugones" (Vida M oderna, M éxico, 19 de octubre de 1916), en 0 bras. M éxico: Fondo de Cultura Económica, pp. 478-481.

Lugones, Leopoldo (h.). 1949. M i padre. Biografía de Leopoldo Lugones. Buenos Aires: Centurión.

Marechal, Leopoldo. 1925. "Retruequea Leopoldo Lugones”, M artín Fierro. Buenos Aires, año II, № 26, diciembre, p. 2.

Martínez Estrada, Ezequiel. 1968. Leopoldo Lugones. Retrato sin retocar. Buenos Aires: Emecé.

M endiola Oñate, Pedro. 2001. Buenos Aires entre dos calles: breve panorama de la vanguardia poética argentina. Alicante: Universidad de Alicante.

M orales, Ernesto y Novillo Quiroga, Diego. 1917. Antología contemporánea de poe tas argentinos. Buenos Aires: Alberto Ferriol.

Noé, Julio. 1926. Antología de la poesía argentina moderna. 1900-1925. Buenos Aires: Nosotros.

Noé, Julio. 1931. Antología dela poesía argentina moderna. 1896-1930. Buenos Aires: El Ateneo.

Noé, Julio. 1960. “La poesía”, en Arrieta, Rafael A. (ed.), Historia de la literatura argentina, tomo IV. Buenos Aires: Peuser, pp. 63-128.

Pagano, José León. 1904. El Parnaso argentino. Poesías selectas, Barcelona, M aucci.

Pagés Larraya, Antonio. 1968. “Leopoldo Lugones" (I y II), Atenea № 420, abriljunio, pp. 31-47; y N os 421-422, julio-diciembre, pp. 125-173.

Pedro, Valentín de. 1927. Nuevo Parnaso argentino. Barcelona: Maucci.

Pozuelo Yvancos, José M aría. 1996. “Canon: ¿estética o pedagogía?", en Insula, M adrid, No 600 , diciembre, pp. 3-4.

Puig, Juan de la Cruz. 1910. Antología de poetas argentinos, 10 vols. Buenos Aires: Martín Biedma e Hijo.

Romagosa, Carlos. 1897. Joyas poéticas americanas. Colección de poesías escogidas originales de autores nacidos en América. Córdoba: Imprenta La M inerva.

Tello, Belisario. 1971. El poeta solariego. La síntesis poético-política de Leopoldo Lugones. Buenos Aires: Theoría.

Vignale, Pedro Juan y Tiempo, César. 1927. Exposición de la actual poesía argentina (1922-1927). Buenos Aires: Minerva. 